\title{
Avaliação da atividade antimicrobiana do alho (Allium sativum Liliaceae) e de seu extrato aquoso
}

FONSECA, G.M.1; PASSOS, T.C.'; NINAHUAMAN, M.F.M.L.'; CAROCI, A.S. .; COSTA, L.S.1

${ }^{1}$ Centro Universitário Adventista de São Paulo, Estrada de Itapecerica, 5859, CEP 05858-001, São Paulo, Brasil. ${ }_{2}^{2}$ Escola de Artes, Ciências e Humanidades da Universidade de São Paulo. Rua Arlindo Béttio, 1000, Ermelino Matarazzo, CEP: 03828-000. São Paulo-Brasil. E-mail acaroci@usp.br.

RESUMO: Objetivou-se avaliar a atividade antimicrobiana do alho (Allium sativum Liliaceae), in natura, e do extrato aquoso, frente à Candida albicans $(\mathbf{C a})$ e a Estreptococos do grupo $\mathrm{B}$ (EGB). O alho in natura e os extratos aquosos 30\% e 170\%, foram submetidos à avaliação da atividade antimicrobiana usando os métodos de Difusão em Ágar pela técnica do disco e do poço. Os resultados mostraram que o alho, in natura, apresentou halo de inibição de 55,3 $\pm 2,6$ milímetros $(\mathrm{mm})$ frente a $\mathbf{C a}$ e de $27,1 \pm 2,6 \mathrm{~mm}$ frente à $\mathbf{E G B}$, enquanto o halo de inibição do miconazol foi de $24 \pm 0,5 \mathrm{~mm}$ e o da Penicilina $\mathrm{G}$ de $29,8 \pm 0,3 \mathrm{~mm}$. O extrato aquoso de alho a $30 \%$ não apresentou atividade antimicrobiana frente à Ca e à EGB. Já o extrato aquoso de alho a $170 \%$ apresentou halo de inibição frente a $\mathbf{C a}$, de $11,3 \pm 0,7 \mathrm{~mm}$ na técnica do disco e de 14,5 \pm 0,9 $\mathrm{mm}$ na técnica do poço, porém não inibiu o crescimento da EGB. Conclui-se que o alho in natura apresentou melhor efeito inibitório frente às cepas de Ca e de EGB.

Palavras-chave: Allium sativum, atividade antimicrobiana, extrato aquoso.

\begin{abstract}
Evaluation of the antimicrobial activity of garlic (Liliaceae Allium sativum) and its aqueous extract. This study aimed to evaluate the antimicrobial activity of fresh garlic (Liliaceae Allium sativum) and its aqueous extracts against Candida albicans ( $\mathbf{C a}$ ) and group B Streptococcus (GBS). Fresh garlic and its aqueous extract in concentrations of $30 \%$ and $170 \%$ were evaluated for their antimicrobial activity using the agar diffusion technique. The results showed that fresh garlic showed a halo of inhibition of $55.3 \pm 2.6$ millimeters $(\mathrm{mm})$ towards $\mathrm{Ca}$ and $27.1 \pm 2.6 \mathrm{~mm}$ towards GBS while the inhibition halo of miconazole was $24 \pm 0.5 \mathrm{~mm}$ and the inhibition halo of Penicillin G was $29.8 \pm 0.3 \mathrm{~mm}$. The aqueous extract of garlic in the concentration of $30 \%$ showed no antimicrobial activity towards Ca and GBS. The aqueous extract of garlic at $170 \%$, showed a halo of inhibition towards $\mathbf{C a}$, of $11.3 \pm 0.7 \mathrm{~mm}$ in the disk technique and $14.5 \pm 0.9 \mathrm{~mm}$ in the well technique, but did not inhibit the growth of GBS. We conclude that the fresh garlic showed a better inhibitory effect against the strains of $\mathbf{C a}$ and GBS.
\end{abstract}

Key words: Allium sativum L., antimicrobial activity, aqueous extract.

\section{INTRODUÇÃO}

Devido ao aumento da resistência aos antimicrobianos em uso, as plantas medicinais têm sido intensamente estudadas como agentes alternativos para a prevenção de doenças e tratamento de infecções em seres humanos e, com o passar dos anos, inúmeras pesquisas foram realizadas mostrando a eficiência e confiabilidade das plantas (Badke et al., 2011; Feitosa et al., 2011).

Existe um número muito grande de espécies vegetais que são consideradas medicinais (Lima et al., 2006), mas muitas ainda não tiveram qualquer avaliação científica do seu uso medicinal, o que é essencial para que possam continuar sendo utilizadas com segurança pela população (Stefanello et al., 2006).

Dentre tantas espécies vegetais, o alho (Allium sativum) é considerado uma especiaria que pertence à família Liliaceae, que contem mais de 700 espécies, incluindo a cebola, o alho-poró, e a cebolinha (Brasil, 2005). O seu cultivo teve origem na Ásia Central e desde a antiguidade era utilizado como alimento ou remédio. No século XXI, o alho continua sendo muito pesquisado devido às qualidades nutricionais e terapêuticas (Mota et al.,

Recebido para publicação em 14/11/2012 
2005).

Allium sativum é uma planta herbácea, caracterizada por um bulbo (cabeça) dividido em dentes (bulbilhos). É um alimento funcional rico em alicina que possui ação antiviral, antifúngica e antibiótica, tem também, considerável teor de selênio agindo como antioxidante. Alguns compostos sulfurados presentes no alho possuem atividade hipotensora, hipoglicemiante, hipocolesterolêmica e antiagregante plaquetária, reduzindo o risco de doenças cardiovasculares. As demais substâncias encontradas no alho possuem atividade imunoestimulatória e antineoplásica (Corzo-Martínez et al., 2007).

Há milhares de anos o Allium sativum e seus extratos têm sido usados para tratar infecções. A maior concentração de fitoquímicos terapêuticos encontra-se nos bulbilhos. Centenas de fitoquímicos bioativos foram identificados sendo os de maior destaque os compostos sulfurados, presentes em quantidades três vezes maiores do que em outros vegetais como a cebola e o brócolis (Cutler \& Wilson, 2004).

A leucorréria vaginal ou corrimento vaginal é uma das afecções mais comuns na mulher durante a idade fértil e um dos principais motivos de consulta médica em atenção primária em saúde. Acomete cerca de um terço de todas as mulheres e um índice bem elevado nas gestantes (Duncan et al., 2004).

As afecções vaginais mais comuns são Candida albicans (Ca), Vaginose bacteriana, Trichomonas vaginalis, Clamydya trachomati e Estreptococos do grupo B (EGB) (Berek, 2008).

A Candida albicans ou monilíase é uma infecção ocasionada pelo crescimento anormal de fungos do tipo levedura na mucosa do trato genital feminino e é também um relevante problema na saúde da mulher (Carreiro et al., 2009). A transmissão pode ser por contato sexual, não sendo este o mais comum. O tratamento medicamentoso mais comum é com Miconazol (Cellini et al., 1996; Freitas et al., 2003).

EGB é encontrado na mulher como saprófita vaginal, é incomum em crianças, mas pode ser encontrada na fase da adolescência. A colonização pela bactéria EGB pode ser transitória, crônica, ou intermitente, e tem sido isolado em culturas do trato genital e/ou gastrointestinal baixo em $10-40 \%$ das mulheres grávidas (Gibbs et al., 2004).

Os estudos sobre a prevalência da colonização pela EGB refletem a preocupação de muitos grupos de pesquisa ao redor do mundo, principalmente os que evidenciam as complicações associadas a este agente e as intervenções eficazes para o seu controle (Pogere et al., 2005).

EGB é um habitante normal do trato gastrintestinal, podendo colonizar a vagina de maneira crônica ou intermitente, em cerca de um terço das mulheres (McCORD et al., 2001). Os antibióticos habitualmente utilizados na quimioprofilaxia são penicilina ou ampicilina e, nos casos de alergia, eritromicina ou clindamicina (Quiroga et al., 2008).

Cerca de 10 a $30 \%$ das grávidas tem o trato vaginal e o reto, colonizadas por EGB (Rezende \& Montenegro, 2008). O local predominante da colonização é o reto, do qual as bactérias são transferidas para a vagina.

Devem-se ter cuidados com o uso abusivo de antibióticos, pois existe a possibilidade de aumentar, quantitativamente, as bactérias, causar infecção neonatal resistente a Penicilina $G$ e aumento da resistência diante dos antibióticos (Peixoto et al., 2004).

Apesar dos antibióticos sintetizados serem fundamentais para o tratamento da maioria das afecções, não é verdade que sejam o remédio para todos os males, nem a solução para todas as afecções. Além disso, alguns antibióticos têm reações adversas e com o tempo o usuário pode apresentar resistência bacteriana (Freitas et al., 2003).

Considerando os fatores citados, anteriormente, este trabalho teve como objetivo avaliar a atividade antimicrobiana do alho, in natura, e do extrato aquoso de alho frente à $\mathrm{Ca}$ e ao EGB.

\section{MATERIAL E MÉTODO}

Trata-se de uma pesquisa experimental com abordagem quantitativa sobre a avaliação da atividade antimicrobiana do alho (Allium sativum, Liliaceae), in natura, e extratos aquosos de alho, frente à levedura $\mathrm{Ca}$ (ATCC \#1023) e à bactéria EGB. O experimento foi conduzido no Laboratório de Microbiologia do Centro Universitário Adventista de São Paulo (UNASP-SP) entre os meses de setembro a novembro de 2011.

\section{Material Vegetal}

Foram preparadas três amostras de extrato aquoso de Allium sativum a $30 \%$ (A8, A12, A24) onde o bulbilho de alho foi imerso em $10 \mathrm{ml}$ de solução fisiológica (Cloreto de Sódio 0,9\%) a temperatura de 37 graus Celsius $\left({ }^{\circ} \mathrm{C}\right)$ por oito horas (A8), doze horas (A12), e vinte e quatro horas (A24). Foi preparada também uma amostra a 170\% (A170), onde o bulbilho de alho ficou imerso em $10 \mathrm{~mL}$ de solução fisiológica durante vinte e quatro horas. Diariamente era retirado e colocado outro na mesma solução. Este procedimento foi repetido por sete dias, sendo que o peso final dos bulbilhos usados foi de 17 gramas (g). Tal processo foi idealizado pelos próprios autores. O alho, in natura, foi descascado e com auxílio de um tubo de vidro, foi cortado em

Rev. Bras. PI. Med., Campinas, v.16, n.3, supl. I, p.679-684, 2014. 
discos com aproximadamente $2,0 \mathrm{~mm}$ de espessura e $8,0 \mathrm{~mm}$ de diâmetro. $O$ peso médio de cada disco foi de $0,18 \pm 0,01 \mathrm{~g}$.

Preparação das Suspensões Microbianas

Para a avaliação da atividade antimicrobiana de Allium sativum foram usadas cepas da levedura Candida albicans (ATCC \#1023) e da bactéria EGB, isolada de cultura de secreção vaginal humana. Os micro-organismos foram diluídos em meio Caldo Nutriente (Himedia ${ }^{\circledR}$ ) até a turvação 0,5 da escala de McFarland (1,5 x $10^{8}$ Unidades formadores de colônia (UFC)/mL) para as bactérias e 1,0 da escala de McFarland (3,0 × 108 UFC/mL) para os fungos. Para este procedimento, utilizaram-se os micro-organismos extraídos das culturas inoculadas, aproximadamente, 24 horas antes.

\section{Preparação dos Meios de Cultura}

As placas de Petri foram vedadas com papel kraft pardo e fita crepe (Cremer ${ }^{\circledR}$ ) indicadora de esterilização, e em seguida foram autoclavadas (Phoenix Luferco ${ }^{\circledR}$ ) com pressão máxima de trabalho de $1,5 \mathrm{Kgf} / \mathrm{cm} 2$, correspondente a $127^{\circ} \mathrm{C}$, durante 30 minutos. Após este processo, os meios de cultura, Ágar sangue Mueller-Hinton (Himedia®) e Ágar Sabouraud Dextrosado (Merck ${ }^{\circledR}$ ), foram distribuídos nas placas de Petri e deixados em estufa bacteriológica (FANEM LTDA, modelo $002 \mathrm{CB}^{\circledR}$ ), por $24 \mathrm{~h}$ a $37^{\circ} \mathrm{C}$, servindo como controle de esterilidade. Após este período ficaram estocadas em geladeira $\left(15^{\circ} \mathrm{C}\right)$ até o momento de uso, não ultrapassando o período de duas semanas.

\section{Método Experimental}

Antes da semeadura, as placas foram deixadas em repouso até atingirem a temperatura ambiente. As suspensões microbianas foram inoculadas uniformemente na superfície do meio de cultura com auxílio de um swab esterelizado (Absorve ${ }^{\circledR}$ ), sendo o Agar Sabouraud Dextrosado (Himedia ${ }^{\circledR}$ ) para Candida albicans e Ágar Sangue de Carneiro Base (Himedia ${ }^{\circledR}$ ) para EGB. As placas permaneceram em repouso por três minutos, em temperatura ambiente, para que as substâncias fossem absorvidas pelos meios de cultura.

Após esta etapa, os discos de Allium sativum, in natura, foram colocados diretamente nas placas com o auxílio de uma pinça estéril. Para os extratos aquosos de Allium sativum nas diferentes concentrações, foram utilizados os métodos descritos por Rios et al., (1988), sendo: Difusão em Ágar, Técnica do Disco e Técnica do Poço.

Os discos de papel secos, esterilizados por radiação gama, sem impregnação, medindo $6 \mathrm{~mm}$ de diâmetro foram colocados nas placas e pressionados suavemente para o contato total com a superfície do Ágar. Sob cada disco colocou-se 20 microlitros $(\mu \mathrm{L})$ do extrato de Allium sativum das diferentes amostras. Com o auxílio de um tubo de vidro preparou-se os poços medindo $10 \mathrm{~mm}$ de diâmetro no centro de cada placa. Em cada poço foi colocado $100 \mu \mathrm{L}$ do extrato aquoso das diferentes amostras.

Como controle negativo foram utilizados discos sem impregnação (branco) e o controle positivo, disco contendo antimicrobianos, sendo: antifúngico Miconazol $50 \mu \mathrm{g}$ para a Candida albicans e Penicilina G (10 UI) para EGB. Todas as placas foram incubadas em estufa de cultura (FANEM LTDA $^{\oplus}$, modelo $002 \mathrm{CB}$ ) a $37^{\circ} \mathrm{C}$, durante 48 horas.

No final deste período observou-se a formação dos halos de inibição do crescimento e esses halos foram medidos em milímetros, utilizando-se régua milimetrada (Waleu $\left.{ }^{\circledR}\right)$.

\section{Análises Estatísticas}

Foi utilizado o software GraphPad® Prism (La Jolla, EUA), versão 5.2, para as análises estatísticas, avaliando as amostras pelo teste Anova, com significância de $5 \%(p<0,05)$. Todos os resultados foram expressos como média \pm desvio padrão (d.p.) da média.

\section{RESULTADOS}

\section{Avaliação de Allium sativum, in natura, pelo Método de Difusão em Ágar \\ O disco de alho, in natura $(0,18 \pm 0,01 \mathrm{~g})$,} frente à levedura $\mathrm{Ca}$ apresentou um halo de inibição de 55,3 $\pm 2,6 \mathrm{~mm}(\mathrm{n}=12)$, enquanto o halo de inibição do controle positivo Miconazol $(50 \mu \mathrm{g})$ foi de $24 \pm 0,5$ $\mathrm{mm}(\mathrm{n}=3)$. Quanto à bactéria EGB o halo de inibição foi de $27,1 \pm 2,6 \mathrm{~mm}(\mathrm{n}=18)$, enquanto o controle positivo Penicilina G (10 UI) apresentou o halo de inibição de 29,8 $\pm 0,3 \mathrm{~mm}(\mathrm{n}=3)$ (Tabela 1).

\section{Avaliação dos extratos aquosos de Allium sativum, pelo Método de Difusão em Ágar . Técnica do Disco}

O extrato aquoso de Allium sativum à $30 \%$ (amostras A8, A12 e A24) não apresentou atividade antimicrobiana frente à $\mathrm{Ca}$ e ao EGB. Já o extrato aquoso de Allium sativum à $170 \%$ (A170) inibiu o crescimento de $\mathrm{Ca}$ apresentando o halo de inibição de 11,3 $\pm 0,7 \mathrm{~mm}(\mathrm{n}=3)$, porém não apresentou atividade antibacteriana $(p>0,05)$ frente ao EGB (Tabela 2).

Avaliação dos extratos aquosos de Allium sativum, pelo Método de Difusão em Ágar Técnica do Poço

Na Técnica do Poço nenhuma das amostras

Rev. Bras. PI. Med., Campinas, v.16, n.3, supl. I, p.679-684, 2014. 
TABELA 1. Diâmetros dos halos de inibição de Allium sativum, in natura, pelo método de difusão em Ágar. São Paulo, 2011.

\begin{tabular}{lll}
\hline Micro-organismos testados & Allium sativum (in natura) & Controle positivo \\
\hline Candida albicans $^{1}$ & $55,3 \pm 2,6 \mathrm{~mm}(\mathrm{n}=12)$ & $\begin{array}{l}\text { Miconazol }(50 \mu \mathrm{gg}) \\
24 \pm 0,5 \mathrm{~mm}(\mathrm{n}=3)\end{array}$ \\
& & Penicilina G (10UI) \\
Estreptococos do grupo $\mathrm{B}^{2}$ & $27,1 \pm 2,6 \mathrm{~mm}(\mathrm{n}=18)$ & $29,8 \pm 0,3 \mathrm{~mm}(\mathrm{n}=3)$ \\
\hline
\end{tabular}

${ }^{1}$ ATCC \#1023; " Micro-organismos de cultura humana.

TABELA 2. Diâmetros dos halos de inibição do extrato aquoso de Allium sativum à $30 \%(A 8, A 12, A 24)$ e $170 \%$ (A170), pelo método de Difusão em Ágar - Técnica do Disco. São Paulo, 2011.

\begin{tabular}{|c|c|c|c|c|c|}
\hline Micro-organismos testados & A8 & A12 & A24 & A170 & Controle positivo \\
\hline Cândida albicans ${ }^{1}$ & $\mathrm{R}$ & $\mathrm{R}$ & $\mathrm{R}$ & $11,3 \pm 0,7 \mathrm{~mm}$ & $\begin{array}{l}\text { Miconazol }(50 \mu \mathrm{g}) \\
24 \pm 0,5 \mathrm{~mm}\end{array}$ \\
\hline Estreptococos do grupo $\mathrm{B}^{2}$ & $\mathrm{R}$ & $\mathrm{R}$ & $\mathrm{R}$ & $\mathrm{R}$ & $\begin{array}{l}\text { Penicilina G (10UI) } \\
29,8 \pm 0,3 \mathrm{~mm}\end{array}$ \\
\hline
\end{tabular}

${ }^{1}$ ATCC \#1023; ${ }^{2}$ Micro-organismos de cultura humana; $\mathrm{R}=$ resistente. $\mathrm{n}=3$ para todas as amostras.

do extrato aquoso de Allium sativum à $30 \%$ (A8, A12 e A24) apresentou a atividade antimicrobiana frente à Ca e ao EGB. Já o extrato de alho à 170\% (A170) apresentou inibição do crescimento de $\mathrm{Ca}$ com o halo de 14,5 $\pm 0,9 \mathrm{~mm}(\mathrm{n}=10)$, porém não apresentou a atividade antibacteriana frente ao EGB (Tabela 3 ).

\section{DISCUSSÃO}

A droga mais indicada e utilizada para o tratamento de Ca é o Miconazol e para o EGB é a Penicilina G, contudo os micro-organismos causadores dessas afecções podem se tornar tolerantes ou resistentes a estas drogas ou mesmo, apresentar reações adversas (Neme, 2006; Freitas et al., 2003), por isso se faz necessário investigar as novas drogas ou as alternativas diferentes de tratamento para diversas doenças.

$\mathrm{O}$ alho (Allium sativum) tem sido utilizado como tratamento de diversas doenças desde a antiguidade (Mota et al., 2005) e alguns estudos mais atuais têm encontrado resultados positivos da sua ação antibacteriana, antifúngica, antiviral, antiprotozoário e anti-helmíntico (Venturoso et al., 2011; Lima et al., 2011; Mantawy et al., 2011).

Os resultados apresentados no presente estudo trouxeram evidências de que o alho apresenta efeito inibitório sob o desenvolvimento microbiano, fato também comprovado por outros estudos (Venturoso et al., 2011; Silva et al., 2012 ; Cohain, 2010; Casella et al., 2012). Estas evidências nos indicam que o alho pode ser considerado uma alternativa para o tratamento de infecções causadas por fungos ou bactérias.

Estudos de Rodrigues et al., (2009) in vitro, também evidenciaram a atividade antifúngica de Allium sativum frente às cepas de $\mathrm{Ca}$ isoladas da cavidade bucal de pacientes submetidos à

TABELA 3. Diâmetros dos halos de inibição do extrato aquoso de Allium sativum à $30 \%$ (A8, A12, A24) e 170\% (A170), pelo método de Difusão em Ágar - Técnica do Poço. São Paulo, 2011.

\begin{tabular}{|c|c|c|c|c|c|}
\hline Micro-organismos testados & A8 & A12 & A24 & A170 & Controle positivo \\
\hline Cândida albicans ${ }^{1}$ & $\begin{array}{l}R \\
(n=3)\end{array}$ & $R(n=3)$ & $R(n=3)$ & $\begin{array}{l}14,5 \pm 0,9 \mathrm{~mm} \\
(\mathrm{n}=10)\end{array}$ & $\begin{array}{l}\text { Miconazol }(50 \mu \mathrm{g}) \\
24 \pm 0,5 \mathrm{~mm}(\mathrm{n}=3)\end{array}$ \\
\hline Estreptococos do grupo $\mathrm{B}^{2}$ & $\begin{array}{l}R \\
(n=3)\end{array}$ & $R(n=3)$ & $R(n=3)$ & $\begin{array}{l}R \\
(n=8)\end{array}$ & $\begin{array}{l}\text { Penicilina G(10UI) } \\
29,8 \pm 0,3 \mathrm{~mm}(\mathrm{n}=3)\end{array}$ \\
\hline
\end{tabular}

${ }^{1}$ ATCC \#1023; ${ }^{2}$ Micro-organismos de cultura humana; $R$ = resistente.

Rev. Bras. PI. Med., Campinas, v.16, n.3, supl. I, p.679-684, 2014. 
radioterapia e de pacientes com doença periodontal. Foi avaliada a atividade antifúngica pela técnica da Concentração Inibitória Mínima (CIM) do extrato aquoso e do extrato alcoólico de bulbilhos de alho íntegro e de alho macerado, sendo que os extratos aquosos e alcoólicos de bulbilhos de alho macerado apresentaram maior atividade antifúngica (Rodrigues et al., 2009).

Estudo de Cohain (2010), in vivo, em mulheres que apresentavam sintomas vaginais crônicos juntamente com a antibioticoterapia, a aplicação do alho intra vaginal eliminou todos os sintomas causados pela bactéria EGB. Das nove mulheres, apenas uma não continuou o tratamento, pois referiu irritabilidade. Concluiu-se que o alho pode ser usado para o tratamento de sintomas vaginais causados pela bactéria EGB. No entanto, mais estudos devem ser feitos para verificar se 0 uso do alho durante a gestação pode prevenir o trabalho de parto prematuro, amniotites e doenças do recém-nascido causados pela bactéria EGB.

Existem também outros estudos que verificaram que o emprego de extratos aquosos, hidroalcoólicos e etanólicos e óleos essenciais de Allium sativum possuiam efeitos inibitórios sobre o crescimento de bactérias e de fungos (Venturoso et al., 2011; Silva, 2012; Venturoso et al., 2010; Casella et al., 2012).

No presente estudo, foi verificado que a solução aquosa de alho íntegro a $30 \%$ não inibiu a atividade antimicrobiana frente à $\mathrm{Ca}$ e a EGB, provavelmente pela baixa concentração de princípio ativo de Allium sativum, pois quando foi aumentada a concentração do extrato aquoso de Allium sativum íntegro a $170 \%$ foi observado atividade antimicrobiana frente à $\mathrm{Ca}$. Já o alho, in natura, aplicado diretamente sobre as placas semeadas com a $\mathrm{Ca}$ apresentou maior halo de inibição do que com o antibiótico testado. Estudo anterior observou que extrato aquoso de alho macerado na concentração de $10 \%$ inibiu o crescimento do fungo Aspergillus niger (Santos et al., 2010).

A partir desses resultados pode-se pressupor que o alho (Allium sativum) possui substâncias com uma ampla gama de ações, incluindo a antibacteriana e a antifúngica, corroborando os resultados de outros estudos que também referem que o alho (Allium sativum) possui atividade antimicrobiana, antiviral, antiprotozoário, antihelmíntico e atribui isso ao efeito da alicina, que é o principal constituinte de Allium sativum (Lima et al., 2011; Cohain, 2010; Rodrigues et al., 2009; Casella et al., 2012).

Os resultados do presente estudo demostram que o alho (Allium sativum), in natura, inibiu o crescimento microbiano, portanto pode ser sugerido para o tratamento de afecções vaginais.

Sabe-se que existem profissionais indicam para mulheres com cultura positiva para Ca e EGB, a introdução intravaginal de um bulbilho de alho por cinco noites ao deitar e a cultura destes microorganismos têm sido negativada. As usuárias não referem ardência ou qualquer outra reação adversa.

Sugere-se a realização de novos estudos com diferentes concentrações, formulações menos irritantes e a aplicação tópica do alho (Allium sativum) na vagina da mulher para avaliar a sua ação terapêutica.

\section{CONCLUSÃO}

O Allium sativum, in natura, inibiu o crescimento de $\mathrm{Ca}$ e de EGB, demonstrando melhor desempenho do que o extrato aquoso à 30 e à $170 \%$. A atividade antimicrobiana de Allium sativum, in natura, frente à $\mathrm{Ca}$, foi maior do que com o uso do

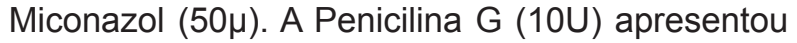
um halo de inibição, discretamente, maior do que o alho, in natura, frente à EGB.

Mais estudos são necessários para confirmar a atividade antimicrobiana do extrato aquoso de Allium sativum e in natura e in vivo, a fim de verificar melhor os seus efeitos. Conclui-se que o alho, in natura e in vitro, possui atividade antimicrobiana.

\section{AGRADECIMENTOS}

Agradecemos ao UNASP-SP e ao Curso de Obstetrícia da Escola de Artes, Ciências e Humanidades da Universidade de São Paulo (USP Leste) pelo suporte técnico, financeiro e acadêmico.

\section{REFERÊNCIA}

BADKE, M.R. et al. Plantas medicinais: o saber sustentado na prática do cotidiano popular. Escola Anna Nery, v.15, n.1, p.132-9, 2011.

BEREK, J.S. Berek \& Novar: Tratado de ginecologia. 14.ed. Rio de Janeiro: Guanabara Koogan; 2008. 1392p.

BRASIL. Ministério da Saúde. Agência Nacional de Vigilância Sanitária. Resolução RDC-276, de 22 de setembro de 2005. Regulamento técnico para especiarias, temperos e molhos. Diário Oficial da União; Poder Executivo, Brasília (DF): 2005.

CARREIRO, D.M. et al. Síndrome Fúngica: uma epidemia oculta. 1.ed. São Paulo: Editora Referência, 2009. $175 p$.

CASELLA, S. et al. The role of diallyl sulfides and dipropyl sulfides in the in vitro antimicrobial activity of the essential oil of garlic, Allium sativum L., and leek, Allium porrum L. Phytotherapy Research, 2012.

CELLINI, L.D.I. et al. Inhibition of Helicobacter pylori by garlic extract. Immunology and Medical Microbiology, v.13, n.44, p.273-7, 1996.

COHAIN, JS. Cases series: Symptomatic Group B

Rev. Bras. PI. Med., Campinas, v.16, n.3, supl. I, p.679-684, 2014. 
Streptococcus vaginitis treated with fresh garlic. Integrative Medicine, v.9, n.3, p. 40-3, 2010.

CORZO-MARTÍNEZ, M. et al. Biological properties of onions and garlic. Trends in Food Science \& Technology, v.18, n.12, p.609-25, 2007

CUTLER, R.R.; WILSON, P. Antibacterial activity of a new, stable, aqueous extract of allicin against methicillinresistant Staphylococcus aureus. British journal of biomedical Science, v. 61, n.2, p.71-4, 2004.

FEITOSA, C.M. et al. Acetylcholinesterase inhibition by somes promising Brazilian medicinal plants. Brazillian Journal of Biologi, v.71, n.3, p.783-9, 2011.

FREITAS, F. et al. Rotinas em obstetrícia, 4.ed. Porto Alegre: Artmed, 2003. 624p.

GIBBS, R.S. et al. Perinatal infections due to group B streptococci. Obstetrics and Gynaecology, v.104, p.1062-76, 2004.

LIMA, C.M.B.L. et al. Ultrastructural study on the morphological changes to male worms of Schistosoma mansoni after in vitro exposure to allicin. Revista da Sociedade Brasileira de Medicina Tropical, v.44, n.3, p.327-30, 2011.

LIMA, M.R.F. et al. The antibiotic activity of some Brazilian medicinal plants. Brazilian Journal of Pharmacognosy, v. 16, n.3, p.300-6, 2006.

MANTAWY, M.M. et al. Therapeutic Effects of Allium sativum and Allium cepa in Schistosoma mansoni experimental infection. Revista do Instituto de Medicina Tropical de São Paulo, v.53, n.3, p.155-63, 2011.

MCCORD, N. et al. A complete audit cycle of intrapartum group B streptococcus prophylaxis. Health bulletin, v. 59, n.4, p.263-7, 2001.

MOTA, J.H. et al. Análise da evolução da produção e relação risco-retorno para a cultura do alho, no Brasil e regiões (1991 a 2000). Horticultura Brasileira, v.23, n.2, p.238-41, 2005.

DUNCAN, B.B. et al. Medicina ambulatorial: condutas de atenção primária baseada em evidências. 3.ed. Porto Alegre: Editora Artmed, 2004. p. 460-4.

NEME, B. Obstetrícia básica. 3.ed. São Paulo: Sarvier, 2006. 1379p.
PEIXOTO, S. et al. Pré-Natal. 3.ed. São Paulo: Editora Roca Ltda, 2004. v.1. 1289p.

POGERE, A. et al. Prevalência de colonização pelo estreptococos do grupo B em gestantes atendidas no ambulatório de pré-natal. Revista Brasileira de Ginecologia e Obstetrícia, v.27, n.4, p.172-8, 2005.

QUIROGA, M. et al. Antibiotic susceptibility patterns and prevalence of group B Streptococcus isolated from pregnant women in Misiones, Argentina. Brazilian Journal of Microbiology, v.39, n.2, p.245-50, 2008.

REZENDE FILHO, M.; MONTENEGRO, C.A.B. Obstetrícia Fundamental. 11.ed. Rio de Janeiro: Guanabara Koogan, 2008. 610p.

RIOS J.L. et al. Screening methods for natural products with antimicrobial activity: a review of the literature. Journal Ethnopharmacology, v.23, n.2-3, p. 127-49, 1988.

RODRIGUES, M.M. et al. Avaliação in vitro da atividade antifúngica do Allium sativum sobre cepas de candida albicans isoladas de cavidade bucal. Revista Periodontia, v.9, n.2, p.124-32, 2009.

SANTOS, M.B. et al.. Efeito inibitório in vitro de extrato vegetal de Allium sativum sobre Aspergillus niger Tiegh. Revista Brasileira de Plantas Medicinais, v.12, n.1, p.13-7, 2010.

SILVA, J.L. et al. Atividade antifúngica de extratos vegetais sobre o crescimento in vitro de fitopatógenos. Revista verde de agroecologia e desenvolvimento sustentável, v. 7, n.1, p. 80-6, 2012.

STEFANELLO, M.E.A. et al. Avaliação da atividade antimicrobiana e citotóxica de extratos de Gochnatia polymorpha ssp floccosa. Revista Brasileira de Farmacognosia, v.16, n.4, p.525-30, 2006.

VENTUROSO, L.R. et al. Influência de diferentes metodologias de esterilização sobre a atividade antifúngica de extratos aquosos de plantas medicinais. Revista Brasileira de Plantas Medicinais, v.12, n.4, p.499-505, 2010.

VENTUROSO, L.R. et al. Atividade antifúngica de extratos vegetais sobre o desenvolvimento de fitopatógenos. Summa Phytopathologica, v.37, n.1, p.18-23, 2011.

Rev. Bras. PI. Med., Campinas, v.16, n.3, supl. I, p.679-684, 2014. 